Article

\title{
Optimization of ZnO Nanorods Concentration in a Micro-Structured Polymeric Composite for Nanogenerators
}

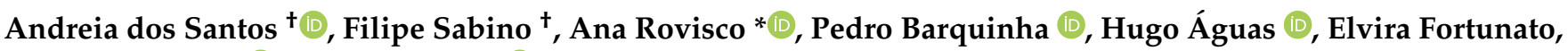 \\ Rodrigo Martins (1) and Rui Igreja *(i)
}

Institute for Nanostructures, Nanomodelling and Nanofabrication (i3N)/Centro de Investigação em Materiais (CENIMAT), Department of Materials Science, NOVA School of Science and Technology (FCT-NOVA) and Center of Excellence in Microelectronics Optoelectronics and Processes (CEMOP)/Instituto de Desenvolvimento de Novas Tecnologias (UNINOVA), NOVA University Lisbon, Campus de Caparica, 2829-516 Caparica, Portugal; ass.santos@campus.fct.unl.pt (A.d.S.); fd.sabino@campus.fct.unl.pt (F.S.); pmcb@fct.unl.pt (P.B.); hma@fct.unl.pt (H.Á.); emf@fct.unl.pt (E.F.); rfpm@fct.unl.pt (R.M.)

* Correspondence: a.rovisco@campus.fct.unl.pt (A.R.); rni@fct.unl.pt (R.I.)

+ These authors contributed equally to this work.

Citation: dos Santos, A.; Sabino, F.; Rovisco, A.; Barquinha, P.; Águas, H.; Fortunato, E.; Martins, R.; Igreja, R. Optimization of $\mathrm{ZnO}$ Nanorods Concentration in a Micro-Structured Polymeric Composite for Nanogenerators. Chemosensors 2021, 9, 27. https://doi.org/10.3390/ chemosensors 9020027

Academic Editor: Simas Rackauskas Received: 28 December 2020

Accepted: 28 January 2021

Published: 31 January 2021

Publisher's Note: MDPI stays neutral with regard to jurisdictional claims in published maps and institutional affiliations.

Copyright: (C) 2021 by the authors Licensee MDPI, Basel, Switzerland. This article is an open access article distributed under the terms and conditions of the Creative Commons Attribution (CC BY) license (https:// creativecommons.org/licenses/by/ $4.0 /)$.

\begin{abstract}
The growing use of wearable devices has been stimulating research efforts in the development of energy harvesters as more portable and practical energy sources alternatives. The field of piezoelectric nanogenerators (PENGs) and triboelectric nanogenerators (TENGs), especially employing zinc oxide $(\mathrm{ZnO})$ nanowires (NWs), has greatly flourished in recent years. Despite its modest piezoelectric coefficient, $\mathrm{ZnO}$ is very attractive due to its sustainable raw materials and the facility to obtain distinct morphologies, which increases its multifunctionality. The integration of $\mathrm{ZnO}$ nanostructures into polymeric matrices to overcome their fragility has already been proven to be fruitful, nevertheless, their concentration in the composite should be optimized to maximize the harvesters' output, an aspect that has not been properly addressed. This work studies a composite with variable concentrations of $\mathrm{ZnO}$ nanorods (NRs), grown by microwave radiation assisted hydrothermal synthesis, and polydimethylsiloxane (PDMS). With a $25 \mathrm{wt} \% \mathrm{ZnO}$ NRs concentration in a composite that was further micro-structured through laser engraving for output enhancement, a nanogenerator (NG) was fabricated with an output of $6 \mathrm{~V}$ at a pushing force of $2.3 \mathrm{~N}$. The energy generated by the NG could be stored and later employed to power small electronic devices, ultimately illustrating its potential as an energy harvesting device.
\end{abstract}

Keywords: energy harvesting; nanogenerators; $\mathrm{ZnO}$ nanorods; microwave assisted hydrothermal synthesis; PDMS; micro-structuring

\section{Introduction}

The establishment of wearables has created new energy supply challenges. This supply is mainly provided by batteries and capacitors, which despite delivering a high output, commonly in a mW scale, are only able to do it for a limited time and with the inconvenience of their bulkiness. Given that low power devices do not require such high outputs, energy scavenged from the environment through energy harvesters can be a viable alternative to batteries and similar devices. In fact, energy harvesters can scavenge energy almost at any time without interruptions and through small devices that are more compatible with wearables [1].

Piezoelectric materials can transduce mechanical energy into electrical energy through strain induced piezoelectric polarization [1]. Several crystalline materials exhibit this type of piezoelectric behavior, namely lead zirconate titanate (PZT) [2-5], gallium nitride $(\mathrm{GaN})$ [6], barium titanate $\left(\mathrm{BaTiO}_{3}\right)$ [7-9], zinc tin oxide $\left(\mathrm{ZnSnO}_{3}\right)$ [10-13], or zinc oxide $(\mathrm{ZnO})[6,14,15]$. In terms of performance, piezoelectric ceramics (such as PZT and $\mathrm{BaTiO}_{3}$ ) have the best output, although their brittle nature limits the device regarding mechanical 
stresses $[16,17]$. From all piezoelectric materials, PZT is by far the most widely employed, presenting a high $\mathrm{d}_{33}$ value of $593 \mathrm{pC} \mathrm{N}^{-1}$ [18], while $\mathrm{ZnO}$ nanoparticles (NPs) present a lower $\mathrm{d}_{33}$ value $\left(\approx 10 \mathrm{pC} \mathrm{N}^{-1}\right)[13,19,20]$. However, the lead content in PZT is highly toxic, and therefore hazardous for the environment [21], which motivates the search for a more conscious option based on a lead-free material. In line with this, $\mathrm{ZnO}$ appears as a good alternative due to its easy fabrication, high abundance, and good performance [22,23].

In the case of the triboelectric effect, which results from the combination of triboelectrification (surface charges generation through the rubbing of two different materials) and electrostatic induction, almost any pair of dissimilar materials can be employed to induce charges mainly through friction [24]. At the nanoscale, these materials can be stimulated by tiny physical motion and the excitation frequency can vary from a few $\mathrm{Hz}$ to thousands of $\mathrm{Hz}$, which is ideal for harvesting random energy from the environment [1].

Nanogenerators (NGs) revolutionized the field of energy harvesting and sensing, while contributing to a sharp growth of publications and research collaborations in these areas of research [15,24-30]. In 2006, Wang and co-workers demonstrated the use of materials at the nanoscale, such as a $\mathrm{ZnO}$ nanowires (NW) array, to fabricate piezoelectric nanogenerators (PENGs) [31]. This was a turning point for piezotronics, and 6 years later a triboelectric nanogenerator (TENG) was developed [32]. The high potential and capability of PENGs and TENGs can lead to many new instruments in different systems. For example, NGs can be used in biomedical and rehabilitation devices as smart sensors, or as a sustainable energy source $[24,25,33-36]$.

Regarding the performance of NGs based on $\mathrm{ZnO}$ nanostructures, a wide range of outputs has been reported [37-40]. The NGs' performance is deeply related to the morphology of the nanostructures, and structure of the electrodes and their material, since one of the drawbacks of these devices is the difficulty in extracting the generated voltages [41]. For NGs based on composites of nanostructures and polymers, the nanostructures concentration should also be considered for the optimization of electric polarization, since an excessively high NPs concentration may lead to partial cancelling of the electrical dipoles, which reduces the output of the device [42,43]. For a NG configuration based on $\mathrm{ZnO}$ NWs vertically grown on both sides of a substrate, with electrodes made of $\mathrm{ZnO} N W s$ coated with gold and a matrix of polydimethylsiloxane (PDMS) surrounding the NWs, output values of $6 \mathrm{~V} / 4 \mathrm{nA} / 0.39 \mathrm{nW} \mathrm{cm}{ }^{-2}$ were achieved with a finger bending [41]. For another NG using $\mathrm{ZnO}$ nanoflowers mixed with PDMS and multiwalled carbon nanotubes (MWCNTs) sandwiched between two aluminum electrodes, an output of $75 \mathrm{~V} / 3.2 \mu \mathrm{A} / 260 \mathrm{~mW} \mathrm{~cm}{ }^{-2}$ was obtained by a person walking with slippers that had the depicted device inbuilt in the soles [43]. These two examples illustrate the versatility of $\mathrm{ZnO}$ nanostructures and the advantages of a composite in the overall device performance.

$\mathrm{ZnO}$ nanostructures with different morphologies were already synthesized, with different properties (electrical, optical, piezoelectric, etc.) observed for each morphology [44]. As an example, nanostructures with smaller sizes demonstrated a more efficient charge transport and a wide band gap, due to the quantum confinement [45]. Another example is the higher efficiency demonstrated by nanostructures with higher surface area (nanoparticles and nanoplates/nanosheets) for sensing applications [46]. Hence, $\mathrm{ZnO}$ nanostructures and thin films have a broad range of applications, from ozone sensors [47] to transistors [48], photocatalysis [49,50], UV sensors [51-53], solar cells [54], Raman platforms [55], amongst others. The high interest of $\mathrm{ZnO}$ nanostructures, particularly nanorods (NRs), for energy harvesting applications [31,56-59], possibly fomented their synthesis though several methods [60-63]. One interesting method is the hydrothermal synthesis under microwave radiation since it is a low-cost, low-temperature, and fast method, yet allowing a high yield production of hexagonal wurtzite structures $[46,64]$. Despite the advantages, ZnO NRs produced through this method have been essentially explored for UV sensors $[46,51,65,66]$, gas sensors [67-70], and photocatalysis [49,71,72], yet not for NGs.

A common approach to produce robust devices using NRs or NWs is their mixture with a polymer matrix, such as polyvinylidene fluoride (PVDF), PDMS, and poly(methyl 
methacrylate) (PMMA), allowing the preservation of their original structure $[40,73,74]$. There are several examples of this approach in which the use of a composite showed good results [37,42,75]. In TENGs, the micro-structuring of the film leads to an increase of the devices triboelectric output, allowing a performance improvement $[43,76]$. The same type of approach was recently employed in PENGs based on $\mathrm{ZnSnO}_{3}$ nanowires, which also showed an enhancement of the piezoelectric properties [13]. Beyond the performance improvement, a polymer matrix increases flexibility and fatigue resistance to mechanical strain [1].

With the previous research as a starting point [13], this work presents the fabrication of a NG based on a composite of ZnO NRs embedded in a PDMS matrix. With the aim of enhancing the devices' performance, the concentration of the NRs in the PDMS film was studied and the composite was further micro-structured through laser engraving technique [77]. The device showed a high stability under stress and over time and, as a proof of concept, a high intensity light-emitting diode (LED) and a commercial household thermometer were powered using the optimized device, testifying the NG's capability as an energy harvester. Furthermore, this work demonstrates that ZnO NRs synthesized through microwave radiation assisted hydrothermal synthesis, instead of the conventional synthesis methods, undoubtedly show a great potential for energy harvesting applications, which proves that it is feasible to obtain functional NGs through low-cost, low-temperature, and fast fabrication processes.

\section{Materials and Methods}

Acrylic molds were produced as described in a previous work [77], and used to microstructure the ZnO@PDMS composite, having aligned micro-cones cavities with a cavity gap $<100 \mu \mathrm{m}$. Briefly, a laser engraving machine (VLS3.50, $50 \mathrm{~W}$, Universal Laser System, Katy, TX, USA) with a $\mathrm{CO}_{2}$ laser beam, a lens' focus length of $2.0 \mathrm{in}$, a focal spot diameter of $127 \mu \mathrm{m}$, a power of $25 \mathrm{~W}$ and a speed of $0.1524 \mathrm{~m} \cdot \mathrm{s}^{-1}$ was employed to engrave acrylic plates with arrays of symmetrical aligned crosses $(100 \mu \mathrm{m})$ with a cross gap of $300 \mu \mathrm{m}$ in an area of $2 \times 2 \mathrm{~cm}^{2}$.

The $\mathrm{ZnO}$ NRs were produced by hydrothermal synthesis assisted by microwave irradiation, as described in reference [78]. Essentially, $3.3 \mathrm{~g}$ of zinc acetate dihydrate (ACS, 98-101.0\%, Fisher Scientific, Hampton, NH, USA) were dissolved in $30 \mathrm{~mL}$ of de-ionized water, and the solution was put in agitation. $9.6 \mathrm{~g}$ of sodium hydroxide (Labkem, Sevilla, Spain) were added to the previous solution. The surfactant solution was produced by mixing $300 \mathrm{~mL}$ of deionized water with $0.09 \mathrm{~g}$ of sodium lauryl sulfate (SLS, $95 \%$, extra pure, from Scharlau, Barcelona, Spain). Then $6 \mathrm{~mL}$ of the first solution were mixed with $15 \mathrm{~mL}$ of the surfactant solution and $30 \mathrm{~mL}$ of 2-ethoxyethanol (Honeywell Research Chemicals, Porto Salvo, Portugal). The final solution was transferred to 3 Teflon ${ }^{\circledR}$ vessels of $20 \mathrm{~mL}$. The vessels were then placed in a microwave (CEM-MarsOne, from CEM, Charlotte, NC, USA) to be heated at $110^{\circ} \mathrm{C}$ for $40 \mathrm{~min}$ (with a temperature ramp of $7 \mathrm{~min}$ and under a power of $600 \mathrm{~W}$ ). The vessels were afterwards cooled down to room temperature and the $\mathrm{ZnO}$ NRs were then washed by successive centrifugation at $4000 \mathrm{rpm}$ for $5 \mathrm{~min}$ with propan-2-ol (ALLRESIST GmbH, Strausberg, Germany) and deionized water, for about 10 times. The NRs were finally dried at $84^{\circ} \mathrm{C}$ for $6 \mathrm{~h}$.

For the fabrication of the NGs, $\mathrm{ZnO}$ NRs were mixed with the PDMS elastomer (Dow Corning, Midland, MI, USA) in a ratio of 15, 20, 25 or $30 \mathrm{wt} \%$, and ethyl acetate from Fluka-Honeywell (Portugal) (enough volume to promote the mixing of elastomer and NRs). After mixing until evaporating most of the solvent volume, the curing agent (Sylgard 184, from Dow Corning, Midland, MI, USA) was added in a weight ratio to elastomer of 1:10, and the mixture was mixed thoroughly before spin-coating at $250 \mathrm{rpm}$ for $90 \mathrm{~s}$, with an acceleration of $100 \mathrm{rpm} \mathrm{s}^{-1}$, on two different substrates: commercial substrates of polyethylene terephthalate (PET) with an indium tin oxide (ITO) thin film deposited on top, PET/ITO (Kintec Company, Hung Hom, Kowloon, Hong Kong), resulting in unstructured NGs; or acrylic molds (5 mm thick, from Dagol, Zambujal, Sesimbra, Portugal), resulting in 
micro-structured NGs. The ZnO@PDMS films were partially cured at $60{ }^{\circ} \mathrm{C}$ for $10 \mathrm{~min}$ to 15 min before placing the PET/ITO substrate directly over the composite. After completing the cure at $60{ }^{\circ} \mathrm{C}$ for $45 \mathrm{~min}$, the micro-structured ZnO@PDMS film with the PET/ITO substrate was peeled off from the mold and assembled with another electrode of PET/ITO with kapton tape (DuPont, Wilmington, DE, USA). In both types of NGs, copper tape (3M, Saint Paul, MN, USA) was used as an extension of each electrode. The main steps to fabricate one micro-structured NG are illustrated in Figure 1a. Figure 1b illustrates a final micro-structured NG with a micro-structuring area of $4 \mathrm{~cm}^{2}$.

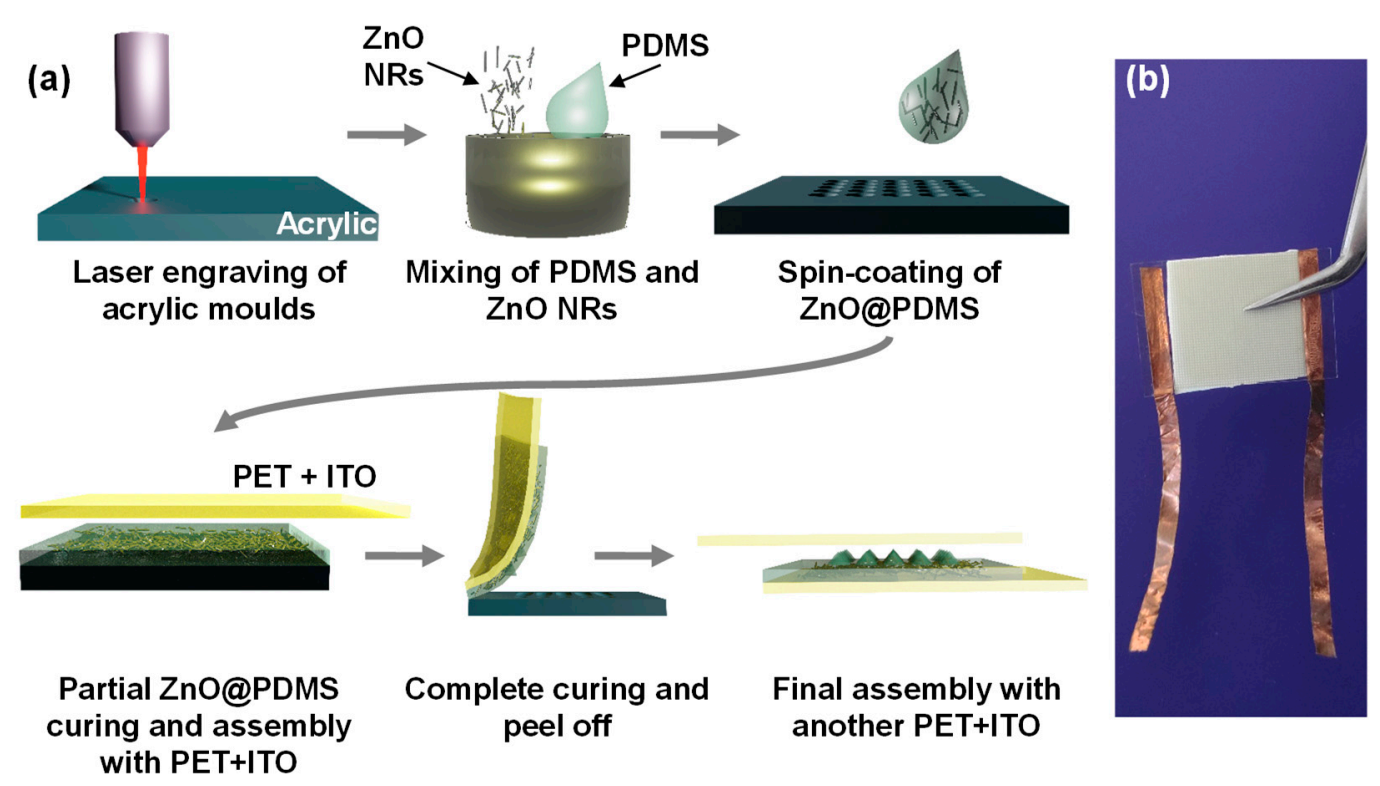

Figure 1. (a) Fabrication steps of a micro-structured nanogenerator (NG) based on a ZnO@PDMS composite. (b) Photograph of a micro-structured NG.

A PANalytical's X'Pert PRO MRD diffractometer (PANalytical B.V., Almelo, The Netherlands) with $\mathrm{Cu} \mathrm{K} \alpha$ radiation $\left(10-60^{\circ} 2 \theta\right.$ range, step size of $0.033^{\circ}$ ) was employed for the structural characterization of ZnO NRs and ZnO@PDMS composites. The morphology analysis of the ZnO NRs was performed with a Carl Zeiss AURIGA CrossBeam (FIB-SEM) workstation (Carl Zeiss Microscopy GmbH, Oberkochen, Germany), while the morphology and EDX analysis of the composite was performed in standard observation mode and EDX mode, respectively, at $15 \mathrm{kV}$, using a tabletop SEM Hitachi TM3030Plus.

A home-made machine with a linear motor and a contact area of $0.3 \mathrm{~cm}^{2}$ was used to deliver a mechanical stimulus of variable force $(0.8 \mathrm{~N}$ to $4.1 \mathrm{~N})$ at a frequency of 0.5 , $1,1.5$, and 2 pushes per second (Figure S1). A digital oscilloscope (Tektronix TDS 2001C, $10 \mathrm{M} \Omega$ input impedance, from Tektronix, Beaverton, OR, USA) was used for voltage measurements, while a potentiostat (Gamry 600, from Gamry Instruments, Philadelphia, PA, USA) was employed for current measurements. The force applied by the home-made machine was measured with a commercial force sensing resistor (Ref. SEN05003) from Interlink Electronics (Camarillo, CA, USA).

\section{Results and Discussion}

\subsection{Morphological and Structural Characterization of ZnO Nanorods and ZnO@PDMS Films}

Figure 2a shows SEM images of a micro-structured ZnO@PDMS film. The film is composed of an array of aligned cones with an average diameter of $300 \mu \mathrm{m}$, an average height of $380 \mu \mathrm{m}$, and a gap inferior to $100 \mu \mathrm{m}$. The close-up views of the SEM images clearly reveal the ZnO NRs homogenously dispersed throughout the PDMS matrix. To verify that the structures were indeed $\mathrm{ZnO} \mathrm{NRs}$, the samples were analyzed through EDX, as presented in Figure 2b, where the zinc element is more concentrated in the referred 
structures, as expected. Figure 2c shows the EDX data, highlighting the main elements present in the ZnO@PDMS film: carbon and silicon (which integrate the PDMS polymeric chains), zinc (which constitutes the ZnO NRs), and oxygen (present in both the PDMS matrix and the NRs). Figure $2 \mathrm{~d}$,e show the SEM images of ZnO NRs, which have an average length and diameter of $(2.3 \pm 0.7) \mu \mathrm{m}$ and $(0.4 \pm 0.2) \mu \mathrm{m}$, respectively. The distribution of lengths and diameters of the NRs can be found in the respective histograms from Figure S2. Figure $2 \mathrm{f}$ presents the XRD diffractogram of ZnO NRs, ZnO@PDMS, and pure PDMS. The peaks observable for the NRs are assigned to the hexagonal wurtzite ZnO structure, with lattice constants of $\mathrm{a}=0.3296 \mathrm{~nm}$ and $\mathrm{c}=0.52065 \mathrm{~nm}$. As expected, those peaks are also present in the ZnO@PDMS composite, yet absent in pure PDMS.
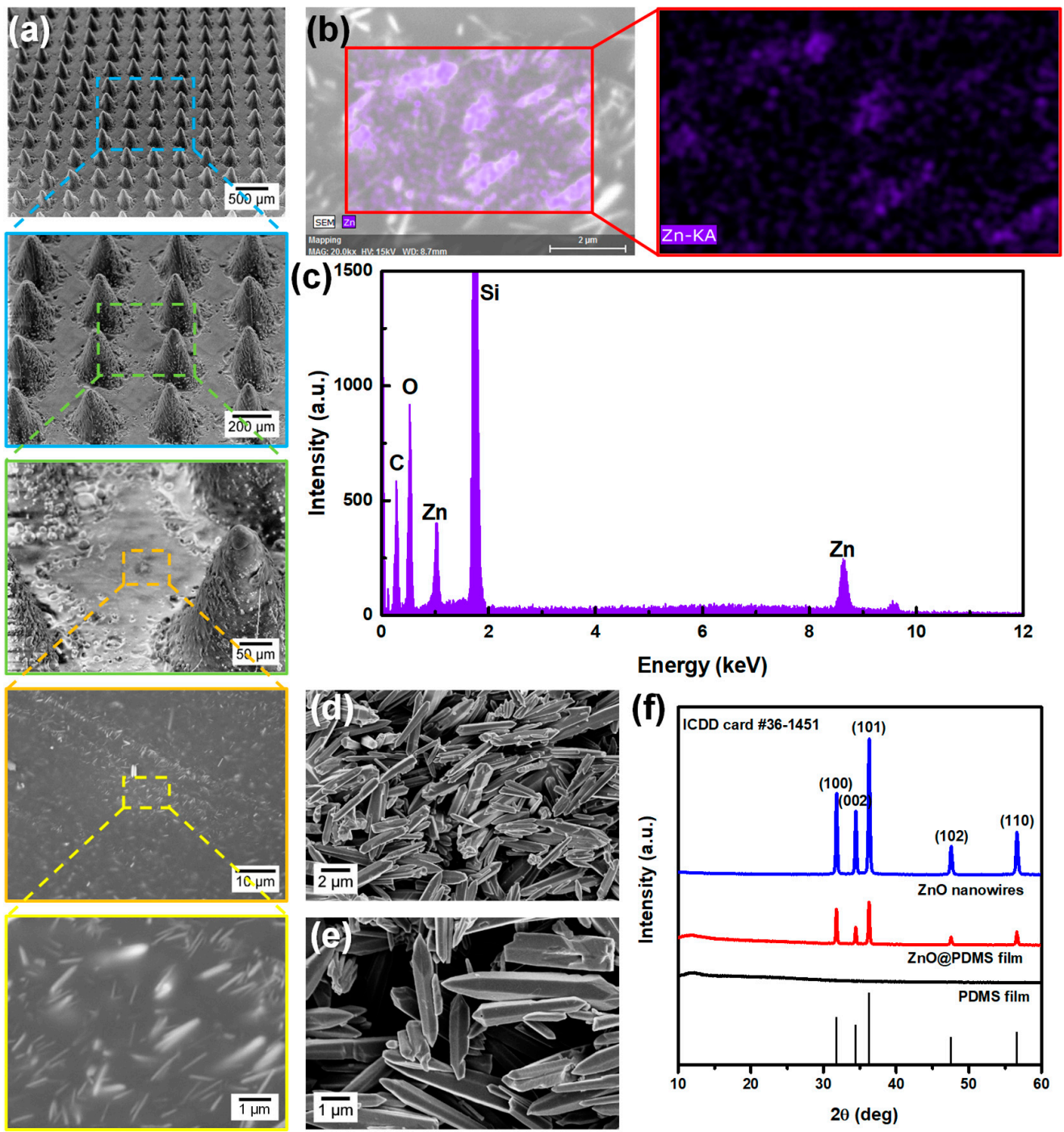

Figure 2. Morphological and structural characterization of the $\mathrm{ZnO}$ nanorods (NRs) and the ZnO@PDMS composite. (a) SEM images of a micro-structured ZnO@PDMS film, with the insets showing closer views of the film (where ZnO NRs are visible in the PDMS matrix). (b) EDX mapping of the ZnO@PDMS film. (c) EDX data from the SEM image in (b). (d,e) SEM images of ZnO NRs. (f) XRD diffractogram of ZnO NRs, ZnO@PDMS film, and pure PDMS. The identification of ZnO was following ICDD card \#36-1451.

\subsection{Piezoelectric Characterization of $\mathrm{ZnO}$ Nanorods}

In a previous work [13], piezoelectric force microscopy was employed in untreated individual $\mathrm{ZnO} \mathrm{NRs}$ for the characterization of their electromechanical properties, as shown in Figure S3. The response is slightly above the noise level and leads to an effective 
piezoelectric constant of $\mathrm{d}_{33}=(9 \pm 2) \mathrm{pm} \cdot \mathrm{V}^{-1}$, in agreement with the values reported for $\mathrm{ZnO}$ nanostructures [20]. Moreover, such work proved that the relaxed NRs do not exhibit static surface charges, which could impact on their electromechanical response [13]. Thus, the findings demonstrate the piezoelectric properties of the individual NRs. The fact that the NRs were obtained through microwave radiation assisted hydrothermal synthesis and still present piezoelectric properties proves that this synthesis technique is feasible to produce functional structures, with the advantages of being faster, low-cost, and using lower temperatures.

\subsection{Optimization of the ZnO Concentration in the ZnO@PDMS Composite}

In order to produce NGs with the highest potential, it is important to evaluate their performance with the $\mathrm{ZnO}$ concentration. In fact, several groups verified that with an increasing mass of piezoelectric particles dispersed in a polymeric matrix there is an output increase, yet beyond a certain mass value, the output starts decreasing $[7,10,79,80]$. Such occurrence may be explained by a possible electrical breakdown due to an excessive nanoparticles concentration, an inefficient dispersion of the nanoparticles in the polymeric matrix, which then prevents the alignment of electric dipoles in a large proportion [10,79], or due to a degradation of electromechanical coupling effects, such as the deformability, with increasing concentration [7].

Figure 3a presents the peak-to-peak voltage with the concentration of $\mathrm{ZnO} N R s$ in the ZnO@PDMS composite. The composites were mechanically stimulated with a home-made bending machine, adapted to exert a pushing force of $2.3 \mathrm{~N}$ at a frequency of 2 pushes per second. There seems to be a trend of increasing voltage with the increase of $\mathrm{ZnO}$ NRs concentration until $25 \mathrm{wt} \%$, after which the output decreases for greater concentrations. This observation is therefore in accordance to what was previously reported for composites with other types of materials $[7,10,79,80]$, with the current work being the first to verify this effect in PDMS composites with ZnO NRs, to the best of the author's knowledge.
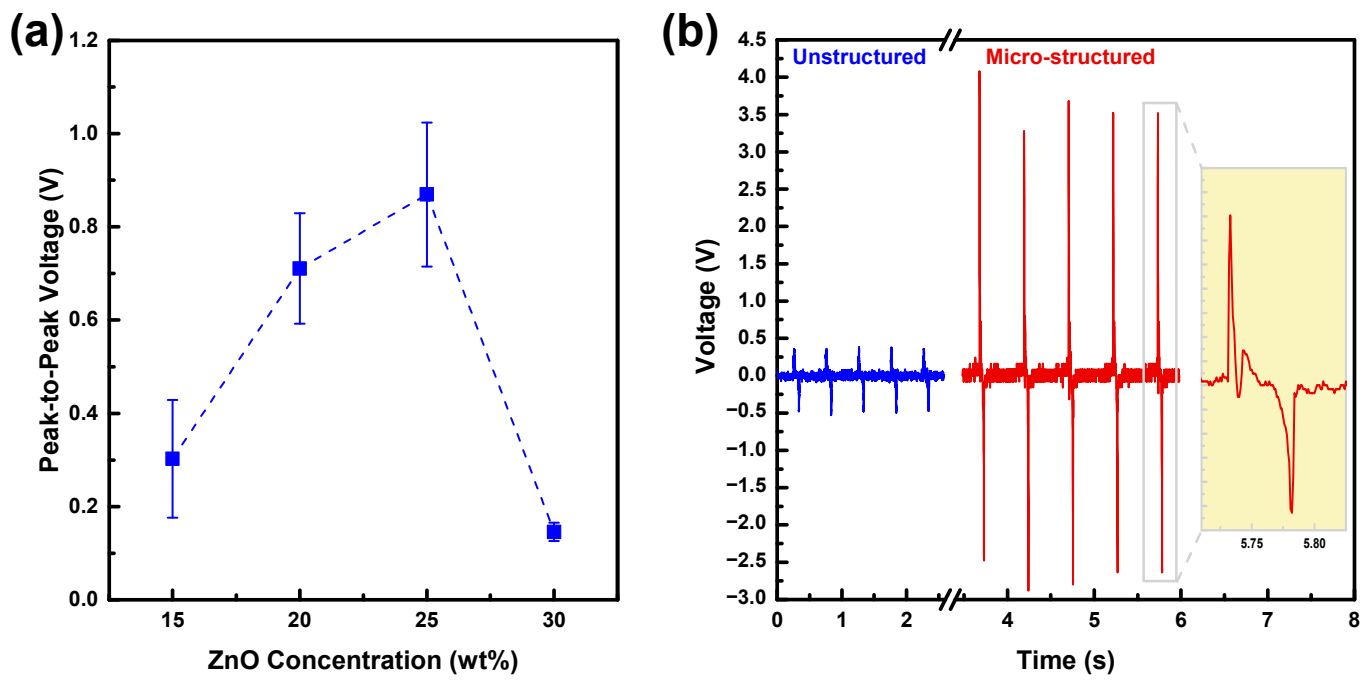

Figure 3. Performance of the ZnO@PDMS composites with the concentration of ZnO NRs. (a) Peak-to-peak open circuit voltage for ZnO@PDMS composites with different concentrations of ZnO NRs. Each point is the average output of 2 to 6 identical devices. (b) Voltage output for an unstructured and a micro-structured NG with a ZnO NRs concentration of $25 \mathrm{wt} \%$. All results were obtained with a mechanical stimulation performed by the home-made bending machine that exerted a pushing force of $2.3 \mathrm{~N}$ at a frequency of 2 pushes per second.

Considering $25 \mathrm{wt} \%$ as the optimum concentration of $\mathrm{ZnO}$ NRs in the composite, two types of NGs were fabricated to further explore and enhance the potential of the composite: an unstructured one and a micro-structured one, with its micro-structuring being based on micro-cones of $380 \mu \mathrm{m}$ height, $300 \mu \mathrm{m}$ diameter, and a gap inferior to $100 \mu \mathrm{m}$, as shown 
in Figure 2a. The output voltage for these two NGs in the same conditions as before is shown in Figure $3 \mathrm{~b}$. The micro-structured NG shows a better performance, achieving a peak-to-peak voltage of $(6.00 \pm 0.7) \mathrm{V}$, against only $(0.87 \pm 0.2) \mathrm{V}$ for the unstructured counterpart. Such enhancement in voltage, about 6 times, may be explained by two effects: an increased efficiency in force delivery to the $\mathrm{ZnO}$ NRs due to the micro-structuring of the composite, reinforcing the piezoelectric effect of the ZnO NRs (as it was verified for a composite of $\mathrm{ZnSnO}_{3} @ \mathrm{PDMS}$ in [13]), and an additional triboelectric effect that arises due to the introduction of air gaps between the ZnO@PDMS composite and the ITO electrode with the micro-structuring. However, it is not trivial to clearly distinguish the isolated contribution of piezoelectric or triboelectric effects to the performance of the NG.

\subsection{Electrical Characterization of ZnO@PDMS NGs}

Given the best performance obtained with a micro-structured NG, this type of device was further characterized regarding its performance for mechanical stimuli of different frequencies, force magnitudes, and applied for long periods for fatigue tests.

Figure $4 \mathrm{a}$ illustrates the performance of the referred NG as a function of the stimulus frequency for a constant force of $2.3 \mathrm{~N}$. As expected, there is an increase in voltage output with the frequency of the mechanical stimulus, as observed by other groups [81-85]. This behavior may be explained by the fact that when the pushing stimuli is faster, the system is unable to efficiently neutralize the induced charges, thus leading to accumulation of residual charges [81].
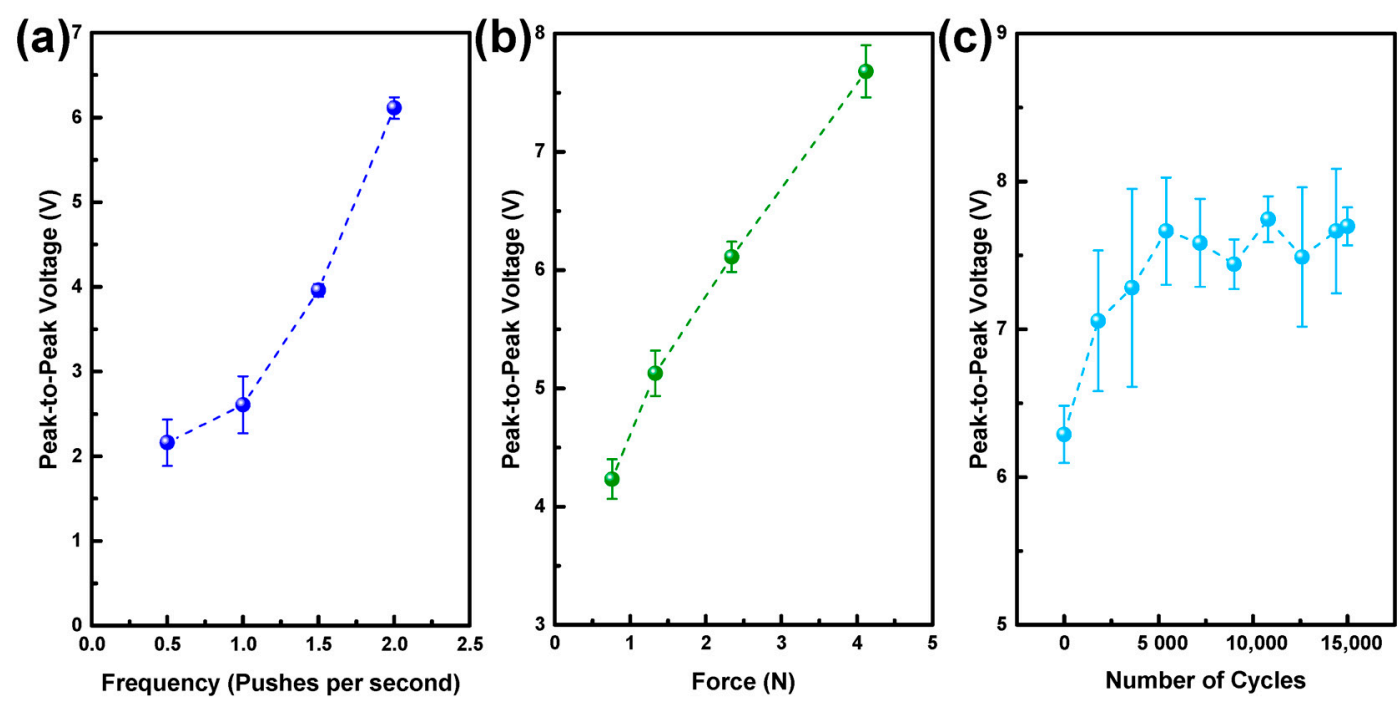

Figure 4. Electrical characterization of a micro-structured ZnO@PDMS NG. Peak-to-peak voltage for (a) a pushing force of $2.3 \mathrm{~N}$ applied at varied frequencies, (b) a pushing frequency of 2 pulses per second with different forces, (c) a pushing force of $2.3 \mathrm{~N}$ applied at 2 pulses per second for 15,000 cycles. Each point represents the average of 5 measurements.

When the frequency of the stimuli is fixed at 2 pushes per second, the output voltage of the NG increases with force, as shown in Figure $4 b$, which highlights the potential of these devices not only for energy harvesting but also for force/pressure sensing. This effect is also widely documented in other works [81,83,85-88] and may be explained by two factors. Firstly, the piezoelectric effect that is present in the NGs. With an increase of the intensity of the mechanical stimulus, the deformation applied to the crystalline structure of the $\mathrm{ZnO}$ NRs increases as well, which induces a larger charge rearrangement and thus translates into a greater piezoelectric signal. Secondly, due to triboelectric effect, mechanical stimuli of increasing force induce a greater rubbing and increase the contact area between the ZnO@PDMS micro-cones and the ITO electrode, thus inducing more charges at their interface. 
Figure 4c shows the peak-to-peak voltage for a fixed pushing force of $2.3 \mathrm{~N}$ applied at 2 pushes per second for 15,000 cycles. The micro-structured NG seems to have a greater voltage with the number of pushing cycles, possibly due to charges accumulation throughout the cycles. After being subjected to 15,000 pushing cycles, the micro-structured NG shows a peak-to-peak voltage of $(7.7 \pm 0.1) \mathrm{V}$. This value proves the robustness of the NG and its potential use in a daily life situation, where it is necessary to have a device able to withstand a great number of cycles without a significant deterioration of its performance.

\subsection{Proof-of-Concept of the NG}

The micro-structured ZnO@PDMS NG was connected to several load resistances $(10 \mathrm{M} \Omega$ to $100 \mathrm{M} \Omega$ ) to evaluate the output voltage and power density with a fixed pushing force of $2.3 \mathrm{~N}$ at 2 pushes per second. As shown in Figure 5a, the peak-to-peak voltage generated by the NG increases with an increasing load resistance. Regarding the power density, despite reaching an apparent peak at $40 \mathrm{M} \Omega$ due to a slight power density decrease for $50 \mathrm{M} \Omega$ and $60 \mathrm{M} \Omega$, which is mainly explained by experimental errors, it hits a maximum peak approximately at $70 \mathrm{M} \Omega$, steadily decreasing afterwards. Therefore, $70 \mathrm{M} \Omega$ is considered to be the load that maximizes the power density at $4.8 \mu \mathrm{W} \mathrm{cm}{ }^{-2}$.

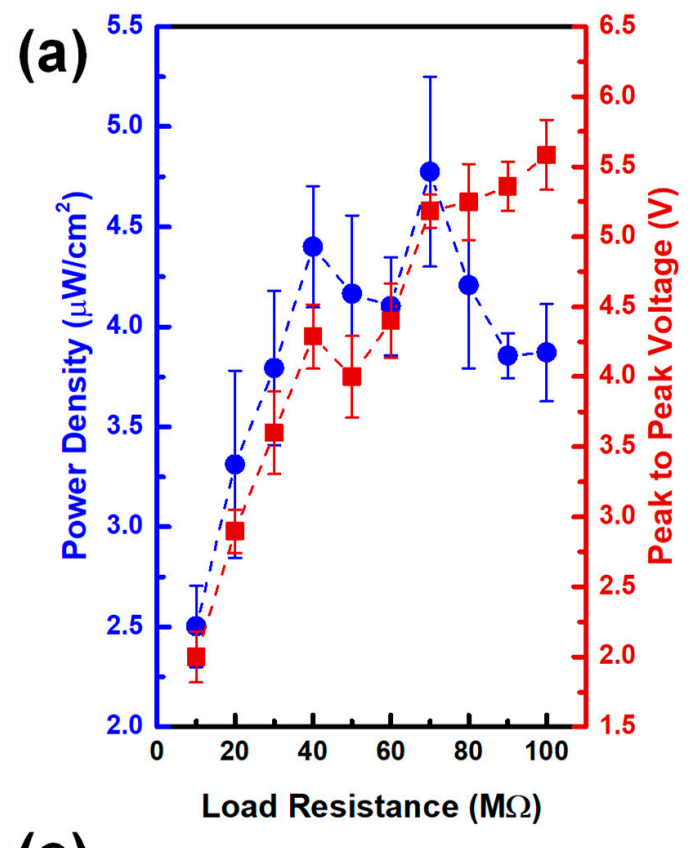

(b)
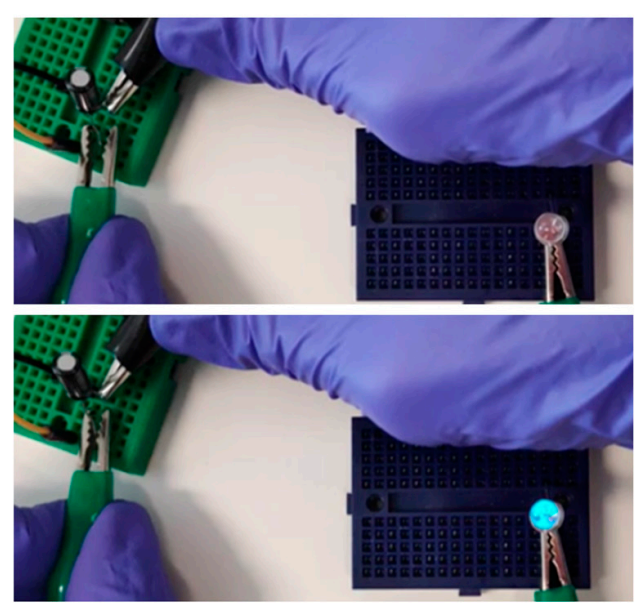

(c)
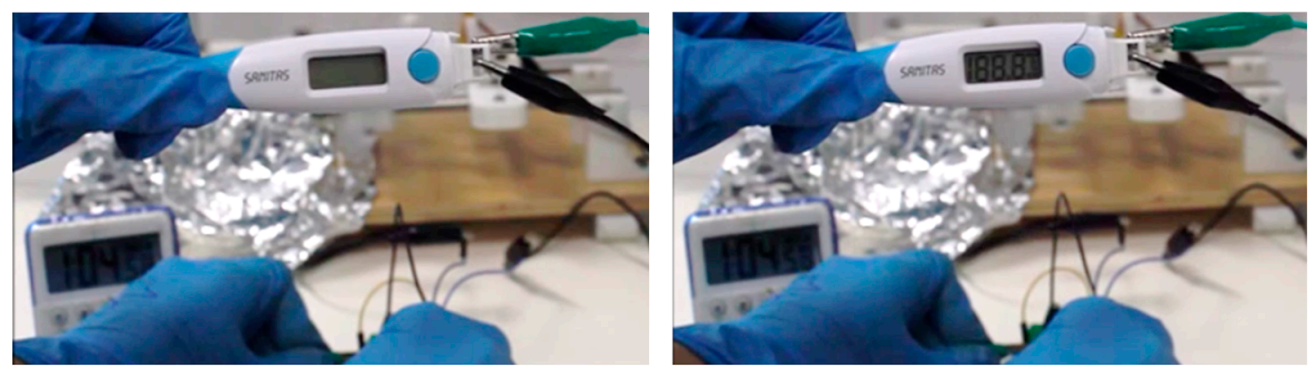

Figure 5. Application of the micro-structured ZnO@PDMS NG, under a pushing force of $2.3 \mathrm{~N}$ at a frequency of 2 pushes per second for several load resistances. (a) Peak-to-peak voltage and power density for several load resistances. Note that each point represents average measurements of 5 outputs. NG being used to charge a $10 \mu \mathrm{F}$ capacitor to power up (b) a blue LED and (c) a digital thermometer. 
To test the practicality of this NG, the device was connected to a full-rectifier bridge and its DC output (for a pushing force of $2.3 \mathrm{~N}$ applied at a frequency of 2 pushes per second) was used to charge a $10 \mu \mathrm{F}$ capacitor. After charging for approximately $1 \mathrm{~h}$, the capacitor (roughly reaching $4 \mathrm{~V}$ and a stored energy of $80 \mu \mathrm{J}$ ) was connected to a blue LED (Ref. 017-1059 from Robert Mauser, Portugal; Video S1) or a digital thermometer (Video S2) to power them up, as illustrated in Figure $5 b$,c. These results show that the NG can generate enough energy to be stored and later used to power up small electronic devices, proving its potential as an effective energy harvester.

\section{Conclusions}

This work reports the use of $\mathrm{ZnO}$ NRs, produced through microwave radiation assisted hydrothermal synthesis, to fabricate energy harvesters. Specifically, the ZnO NRs were mixed with PDMS to achieve a flexible composite suitable for robust NGs.

Even though the $\mathrm{ZnO}$ NRs were produced through a faster and low-cost method, they still presented piezoelectric properties, namely a $\mathrm{d}_{33}$ of $(9 \pm 2) \mathrm{pm} \mathrm{V}^{-1}$, which are expectable for these structures when produced through conventional methods, thus validating the synthesis technique as a proper way to obtain piezoelectric and functional structures.

The influence of the $\mathrm{ZnO}$ NRs concentration in the devices' performance is clear. After the optimization of the NRs concentration, micro-structuring was added to the composite films, resulting in a great enhancement on the performance of the nanogenerators. The micro-cones contributed to the performance improvement through two aspects: first, the structuring increases the efficiency in force delivery to the $\mathrm{ZnO} N R s$, increasing their piezoelectric output; second, the structuring introduced air gaps between the composite and the ITO electrodes, which is beneficial to potentiate the triboelectric effect. Nanogenerators with a ZnO@PDMS micro-structured into micro-cones and a ZnO NRs concentration of $25 \mathrm{wt} \%$ presented a peak-to-peak voltage of approximately $6 \mathrm{~V}$ at a pushing frequency of 2 pushes per second with a pushing force of only $2.3 \mathrm{~N}$.

The nanogenerators could withstand 15,000 pushing cycles without a performance deterioration, which shows their robustness, being also able to charge a $10 \mu \mathrm{F}$ capacitor until storing approximately $80 \mu \mathrm{J}$ (after $1 \mathrm{~h}$ of pushing) for powering a blue LED or a digital thermometer. With an external load of $70 \mathrm{M} \Omega$, the nanogenerators could deliver a power density of $4.8 \mu \mathrm{W} \mathrm{cm}{ }^{-2}$. These results highlight the potential of these flexible nanogenerators, with an easy, low-cost, low-temperature, and scalable fabrication process, for energy harvesting and real-life applications such as powering of small electronic devices.

Supplementary Materials: The following are available online at https:/ / www.mdpi.com/2227-9 040/9/2/27/s1, Figure S1: Photographs of the bending machine employed to exert a controlled force on the NGs; Figure S2: Histograms for the (a) length, and (b) diameter of the ZnO NRs produced synthesized through microwave assisted hydrothermal synthesis; Figure S3: Piezoresponse characterization of ZnO NRs through piezoelectric force microscopy; Video S1: Powering a blue LED; Video S2: Powering a digital thermometer.

Author Contributions: Conceptualization, A.d.S. and A.R.; methodology and validation, F.S. and A.d.S.; formal analysis, A.d.S., F.S. and A.R.; writing-original draft preparation, A.d.S., F.S. and A.R.; writing—review and editing, A.d.S., F.S., A.R., R.I., H.Á., P.B., E.F. and R.M.; supervision, R.I.; funding acquisition, P.B., E.F. and R.M. All authors have read and agreed to the published version of the manuscript.

Funding: This work is funded by FEDER funds through the COMPETE 2020 Programme and National Funds through the FCT-Fundação para a Ciência e a Tecnologia, I.P., under the scope of the project UIDB/50025/2020. A.d.S. acknowledges the support from the Portuguese Foundation for Science and Technology and MIT-Portugal through the scholarship PD/BD/105876/2014. This work also received funding from the European Community's H2020 program under grant agreement No. 716510 (ERC-2016-STG TREND) and No. 685758 (1D-Neon).

Institutional Review Board Statement: Not applicable. 
Informed Consent Statement: Not applicable.

Data Availability Statement: The data presented in this study are available on request from the corresponding author.

Acknowledgments: The authors would like to acknowledge Diogo Coelho and Renato Nora for the help with the $\mathrm{ZnO}$ nanorods syntheses.

Conflicts of Interest: The authors declare no conflict of interest. The funders had no role in the design of the study; in the collection, analyses, or interpretation of data; in the writing of the manuscript, or in the decision to publish the results.

\section{References}

1. Wang, Z.L. Nanogenerators for Self-Powered Devices and Systems, 1st ed.; Georgia Institute of Technology: Atlanta, GA, USA, 2011; ISBN 9781450780162.

2. Kanno, I.; Kotera, H.; Wasa, K. Measurement of transverse piezoelectric properties of PZT thin films. Sens. Actuators A Phys. 2003, 107, 68-74. [CrossRef]

3. Briscoe, J.; Dunn, S. Piezoelectric nanogenerators-A review of nanostructured piezoelectric energy harvesters. Nano Energy 2015, 14, 15-29. [CrossRef]

4. Park, K., II; Son, J.H.; Hwang, G.T.; Jeong, C.K.; Ryu, J.; Koo, M.; Choi, I.; Lee, S.H.; Byun, M.; Wang, Z.L.; et al. Highly-efficient, flexible piezoelectric PZT thin film nanogenerator on plastic substrates. Adv. Mater. 2014, 26, 2514-2520. [CrossRef]

5. Niu, X.; Jia, W.; Qian, S.; Zhu, J.; Zhang, J.; Hou, X.; Mu, J.; Geng, W.; Cho, J.; He, J.; et al. High-Performance PZT-Based Stretchable Piezoelectric Nanogenerator. ACS Sustain. Chem. Eng. 2019, 7, 979-985. [CrossRef]

6. Pearton, S.J.; Re, F. Wide Bandgap Semiconductor One-Dimensional Nanostructures for Applications in Nanoelectronics and Nanosensors. Nanomater. Nanotechnol. 2013, 3, 1-15. [CrossRef]

7. Lapčinskis, L.; Mā Lnieks, K.; Linarts, A.; Blūms, J.; Šmits, K.N.; Järvekülg, M.; Knite, M.R.; Šutka, A. Hybrid Tribo-Piezo-Electric Nanogenerator with Unprecedented Performance Based on Ferroelectric Composite Contacting Layers. ACS Appl. Energy Mater. 2019, 2, 4027-4032. [CrossRef]

8. Chen, X.; Li, X.; Shao, J.; An, N.; Tian, H.; Wang, C.; Han, T.; Wang, L.; Lu, B. High-Performance Piezoelectric Nanogenerators with Imprinted P(VDF-TrFE)/BaTiO 3 Nanocomposite Micropillars for Self-Powered Flexible Sensors. Small 2017, 13, 1604245. [CrossRef]

9. Gao, J.; Xue, D.; Liu, W.; Zhou, C.; Ren, X. Recent Progress on $\mathrm{BaTiO}_{3}$-Based Piezoelectric Ceramics for Actuator Applications. Actuators 2017, 6, 24. [CrossRef]

10. Guo, R.; Guo, Y.; Duan, H.; Li, H.; Liu, H. Synthesis of orthorhombic perovskite-type $\mathrm{ZnSnO}_{3}$ single-crystal nanoplates and their application in energy harvesting. ACS Appl. Mater. Interfaces 2017, 9, 8271. [CrossRef]

11. Wu, J.M.; Xu, C.; Zhang, Y.; Wang, Z.L. Lead-Free Nanogenerator Made from. ACS Nano 2012, 6, 4335-4340. [CrossRef]

12. Wu, J.M.; Xu, C.; Zhang, Y.; Yang, Y.; Zhou, Y.; Wang, Z.L. Flexible and transparent nanogenerators based on a composite of lead-free $\mathrm{ZnSnO}_{3}$ triangular-belts. Adv. Mater. 2012, 24, 6094-6099. [CrossRef]

13. Rovisco, A.; dos Santos, A.; Cramer, T.; Martins, J.; Branquinho, R.; Águas, H.; Fraboni, B.; Fortunato, E.; Martins, R.; Igreja, R.;

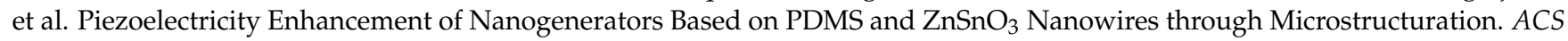
Appl. Mater. Interfaces 2020, 12, 18421-18430. [CrossRef]

14. Zhao, Y.; Lai, X.; Deng, P.; Nie, Y.; Zhang, Y.; Xing, L.; Xue, X. Pt/ZnO nanoarray nanogenerator as self-powered active gas sensor with linear ethanol sensing at room temperature. Nanotechnology 2014, 25, 115502. [CrossRef]

15. Tan, D.; Willatzen, M.; Wang, Z.L. Out-of-Plane Polarization in Bent Graphene-Like Zinc Oxide and Nanogenerator Applications. Adv. Funct. Mater. 2020, 30, 1-8. [CrossRef]

16. Anton, S.R.; Sodano, H.A. A review of power harvesting using piezoelectric materials (2003-2006). Smart Mater. Struct. 2007, 16, R1. [CrossRef]

17. Choi, W.J.; Jeon, Y.; Jeong, J.H.; Sood, R.; Kim, S.G. Energy harvesting MEMS device based on thin film piezoelectric cantilevers. J. Electroceramics 2006, 17, 543-548. [CrossRef]

18. Safari, A. Piezoelectric and Acoustic Materials for Transducer Applications; Safari, A., Akdoğan, E.K., Eds.; Springer: Boston, MA, USA, 2008; ISBN 978-0-387-76538-9.

19. Fan, H.J.; Lee, W.; Hauschild, R.; Alexe, M.; Le Rhun, G.; Scholz, R.; Dadgar, A.; Nielsch, K.; Kalt, H.; Krost, A.; et al. Templateassisted large-scale ordered arrays of ZnO pillars for optical and piezoelectric applications. Small 2006, 2, 561-568. [CrossRef]

20. Broitman, E.; Soomro, M.Y.; Lu, J.; Willander, M.; Hultman, L. Nanoscale piezoelectric response of ZnO nanowires measured using a nanoindentation technique. Phys. Chem. Chem. Phys. 2013, 15, 11113-11118. [CrossRef]

21. Ibn-Mohammed, T.; Reaney, I.M.; Koh, S.C.L.; Acquaye, A.; Sinclair, D.C.; Randall, C.A.; Abubakar, F.H.; Smith, L.; Schileo, G.; Ozawa-Meida, L. Life cycle assessment and environmental profile evaluation of lead-free piezoelectrics in comparison with lead zirconate titanate. J. Eur. Ceram. Soc. 2018, 38, 4922-4938. [CrossRef]

22. Shetti, N.P.; Bukkitgar, S.D.; Reddy, K.R.; Reddy, C.V.; Aminabhavi, T.M. ZnO-based nanostructured electrodes for electrochemical sensors and biosensors in biomedical applications. Biosens. Bioelectron. 2019, 141, 111417. [CrossRef] 
23. Yin, B.; Qiu, Y.; Zhang, H.; Lei, J.; Chang, Y.; Ji, J.; Luo, Y.; Zhao, Y.; Hu, L. Piezoelectric effect of 3-D ZnO nanotetrapods. RSC Adv. 2015, 5, 11469-11474. [CrossRef]

24. Sripadmanabhan Indira, S.; Aravind Vaithilingam, C.; Oruganti, K.S.P.; Mohd, F.; Rahman, S. Nanogenerators as a Sustainable Power Source: State of Art, Applications, and Challenges. Nanomaterials 2019, 9, 773. [CrossRef]

25. Lin, Z. Piezoelectric and triboelectric nanogenerators: Trends and impacts. Nano Today 2018, 22, 8-11.

26. Lin, H.-I.; Wuu, D.-S.; Shen, K.-C.; Horng, R.-H. Fabrication of an Ultra-Flexible ZnO Nanogenerator for Harvesting Energy from Respiration. ECS J. Solid State Sci. Technol. 2013, 2, P400-P404. [CrossRef]

27. Rajagopalan, P.; Singh, V.; Palani, I.A.; Kim, S.J. Superior response in ZnO nanogenerator via interfaced heterojunction for novel smart gas purging system. Extrem. Mech. Lett. 2019, 26, 18-25. [CrossRef]

28. Zhang, X.; Yang, D.; Qiu, Y.; Nie, Y.; Chu, H.; Zhang, H.; Hu, L. Improvement in the Piezoelectric Performance of a ZnO Nanogenerator by a ZnO/Spiro-MeOTAD ps-n Heterojunction. Phys. Status Solidi Appl. Mater. Sci. 2019, 216, 1800717. [CrossRef]

29. Zhao, Y.; Fu, Y.; Wang, P.; Xing, L.; Xue, X. Highly stable piezo-immunoglobulin-biosensing of a $\mathrm{SiO}_{2} / \mathrm{ZnO}_{\text {nanogenerator as a }}$ self-powered/active biosensor arising from the field effect influenced piezoelectric screening effect. Nanoscale 2015, 7, 1904-1911. [CrossRef]

30. Kumar, A.; Gullapalli, H.; Balakrishnan, K.; Botello-Mendez, A.; Vajtai, R.; Terrones, M.; Ajayan, P.M. Flexible ZnO-cellulose nanocomposite for multisource energy conversion. Small 2011, 7, 2173-2178. [CrossRef]

31. Wang, Z.L.; Song, J. Piezoelectric Nanogenerators Based on Zinc Oxide Nanowire Arrays. Science 2006, 312, 242-246. [CrossRef]

32. Fan, F.-R.; Tian, Z.-Q.; Lin Wang, Z. Flexible triboelectric generator. Nano Energy 2012, 1, 328-334. [CrossRef]

33. Hou, T.C.; Yang, Y.; Zhang, H.; Chen, J.; Chen, L.J.; Lin Wang, Z. Triboelectric nanogenerator built inside shoe insole for harvesting walking energy. Nano Energy 2013, 2, 856-862. [CrossRef]

34. Li, T.; Zou, J.; Xing, F.; Zhang, M.; Cao, X.; Wang, N. From Dual-Mode Triboelectric Nanogenerator to Smart Tactile Sensor: A Multiplexing Design. ACS Nano 2017, 11, 3950-3956. [CrossRef]

35. Voiculescu, I.; Li, F.; Kowach, G.; Su, H.; Lee, K.L. Wearable and stretchable piezoelectric nanogenerator for skin applications. In Proceedings of the 2018 Design of Medical Devices Conference, Minneapolis, MN, USA, 9-12 April 2018.

36. Fu, Y.Q.; Luo, J.K.; Du, X.Y.; Flewitt, A.J.; Li, Y.; Markx, G.H.; Walton, A.J.; Milne, W.I. Recent developments on ZnO films for acoustic wave based bio-sensing and microfluidic applications: A review. Sens. Actuators B Chem. 2010, 143, 606-619. [CrossRef]

37. Li, J.; Chen, S.; Liu, W.; Fu, R.; Tu, S.; Zhao, Y.; Dong, L.; Yan, B.; Gu, Y. High Performance Piezoelectric Nanogenerators Based on Electrospun ZnO Nanorods/Poly(vinylidene fluoride) Composite Membranes. J. Phys. Chem. C 2019, 123, 11378-11387. [CrossRef]

38. He, W.; Qian, Y.; Lee, B.S.; Zhang, F.; Rasheed, A.; Jung, J.E.; Kang, D.J. Ultrahigh Output Piezoelectric and Triboelectric Hybrid Nanogenerators Based on ZnO Nanoflakes/Polydimethylsiloxane Composite Films. ACS Appl. Mater. Interfaces 2018, 10, 44415-44420. [CrossRef]

39. Son, M.; Jang, H.; Lee, M.S.; Yoon, T.H.; Lee, B.H.; Lee, W.; Ham, M.H. Flexible Transparent Nanogenerators Utilizing ShapeModulated ZnO Nanorod Arrays on Graphene Electrodes. Adv. Mater. Technol. 2018, 3, 1700355. [CrossRef]

40. Zhu, G.; Yang, R.; Wang, S.; Wang, Z.L. Flexible High-Output Nanogenerator Based on Lateral ZnO Nanowire Array. Nano Lett. 2010, 10, 3151-3155. [CrossRef]

41. Saravanakumar, B.; Mohan, R.; Thiyagarajan, K.; Kim, S.J. Fabrication of a ZnO nanogenerator for eco-friendly biomechanical energy harvesting. RSC Adv. 2013, 3, 16646-16656. [CrossRef]

42. Alluri, N.R.; Chandrasekhar, A.; Vivekananthan, V.; Purusothaman, Y.; Selvarajan, S.; Jeong, J.H.; Kim, S.-J. Scavenging Biomechanical Energy Using High-Performance, Flexible $\mathrm{BaTiO}_{3}$ Nanocube/PDMS Composite Films. ACS Sustain. Chem. Eng. 2017, 5, 4730-4738. [CrossRef]

43. Kim, D.H.; Dudem, B.; Yu, J.S. High-Performance Flexible Piezoelectric-Assisted Triboelectric Hybrid Nanogenerator via Polydimethylsiloxane-Encapsulated Nanoflower-like ZnO Composite Films for Scavenging Energy from Daily Human Activities. ACS Sustain. Chem. Eng. 2018, 6, 8525-8535. [CrossRef]

44. Nunes, D.; Pimentel, A.; Gonçalves, A.; Pereira, S.; Branquinho, R.; Barquinha, P.; Fortunato, E.; Martins, R. Metal oxide nanostructures for sensor applications. Semicond. Sci. Technol. 2019, 34, 043001. [CrossRef]

45. Neikov, O.D.; Yefimov, N.A. Nanopowders. In Handbook of Non-Ferrous Metal Powders; Elsevier: Amsterdam, The Netherlands, 2019; pp. 271-311.

46. Pimentel, A.; Samouco, A.; Nunes, D.; Araújo, A.; Martins, R.; Fortunato, E. Ultra-Fast Microwave Synthesis of ZnO Nanorods on Cellulose Substrates for UV Sensor Applications. Materials 2017, 10, 1308. [CrossRef]

47. Pimentel, A.C.; Gonçalves, A.; Marques, A.; Martins, R.; Fortunato, E. Zinc Oxide Thin Films used as an Ozone Sensor at Room Temperature. MRS Proc. 2006, 915, 0915-R07-04. [CrossRef]

48. Fortunato, E.M.C.; Barquinha, P.M.C.; Pimentel, A.C.M.B.G.; Gonçalves, A.M.F.; Marques, A.J.S.; Martins, R.F.P.; Pereira, L.M.N. Wide-bandgap high-mobility ZnO thin-film transistors produced at room temperature. Appl. Phys. Lett. 2004, 85, 2541-2543. [CrossRef]

49. Pimentel, A.; Rodrigues, J.; Duarte, P.; Nunes, D.; Costa, F.M.; Monteiro, T.; Martins, R.; Fortunato, E. Effect of solvents on ZnO nanostructures synthesized by solvothermal method assisted by microwave radiation: A photocatalytic study. J. Mater. Sci. 2015, 50, 5777-5787. [CrossRef] 
50. Rodrigues, J.; Pimentel, A.; Fortunato, E.; Monteiro, T.; Costa, F.M. Photocatalytic Activity of Laser-Processed ZnO Micro/Nanocrystals. Phys. Status Solidi 2018, 215, 1800155. [CrossRef]

51. Pimentel, A.; Ferreira, S.; Nunes, D.; Calmeiro, T.; Martins, R.; Fortunato, E. Microwave Synthesized ZnO Nanorod Arrays for UV Sensors: A Seed Layer Annealing Temperature Study. Materials 2016, 9, 299. [CrossRef]

52. Figueira, J.; Gaspar, C.; Carvalho, J.T.; Loureiro, J.; Fortunato, E.; Martins, R.; Pereira, L. Sustainable Fully Printed UV Sensors on Cork Using Zinc Oxide/Ethylcellulose Inks. Micromachines 2019, 10, 601. [CrossRef]

53. Yang, F.; Guo, J.; Zhao, L.; Shang, W.; Gao, Y.; Zhang, S.; Gu, G.; Zhang, B.; Cui, P.; Cheng, G.; et al. Tuning oxygen vacancies and improving UV sensing of $\mathrm{ZnO}$ nanowire by micro-plasma powered by a triboelectric nanogenerator. Nano Energy 2020, 67, 104210. [CrossRef]

54. Rodrigues, J.; Cerqueira, A.F.R.; Sousa, M.G.; Santos, N.F.; Pimentel, A.; Fortunato, E.; da Cunha, A.F.; Monteiro, T.; Costa, F.M. Exploring the potential of laser assisted flow deposition grown $\mathrm{ZnO}$ for photovoltaic applications. Mater. Chem. Phys. 2016, 177, 322-329. [CrossRef]

55. Pimentel, A.; Araújo, A.; Coelho, B.; Nunes, D.; Oliveira, M.; Mendes, M.; Águas, H.; Martins, R.; Fortunato, E. 3D ZnO/Ag Surface-Enhanced Raman Scattering on Disposable and Flexible Cardboard Platforms. Materials 2017, 10, 1351. [CrossRef]

56. Yu, A.; Li, H.; Tang, H.; Liu, T.; Jiang, P.; Wang, Z.L. Vertically integrated nanogenerator based on ZnO nanowire arrays. Phys. Status Solidi Rapid Res. Lett. 2011, 5, 162-164. [CrossRef]

57. Lee, M.; Chen, C.-Y.; Wang, S.; Cha, S.N.; Park, Y.J.; Kim, J.M.; Chou, L.-J.; Wang, Z.L. A Hybrid Piezoelectric Structure for Wearable Nanogenerators. Adv. Mater. 2012, 24, 1759-1764. [CrossRef] [PubMed]

58. Bai, S.; Zhang, L.; Xu, Q.; Zheng, Y.; Qin, Y.; Wang, Z.L. Two dimensional woven nanogenerator. Nano Energy $2013,2,749-753$. [CrossRef]

59. Zhang, Y.; Liu, C.; Liu, J.; Xiong, J.; Liu, J.; Zhang, K.; Liu, Y.; Peng, M.; Yu, A.; Zhang, A.; et al. Lattice Strain Induced Remarkable Enhancement in Piezoelectric Performance of ZnO-Based Flexible Nanogenerators. ACS Appl. Mater. Interfaces 2016, 8, $1381-1387$. [CrossRef]

60. Yi, G.C.; Wang, C.; Park, W. Il ZnO nanorods: Synthesis, characterization and applications. Semicond. Sci. Technol. 2005, 20, S22-S34. [CrossRef]

61. Liu, B.; Zeng, H.C. Hydrothermal synthesis of $\mathrm{ZnO}$ nanorods in the diameter regime of $50 \mathrm{~nm}$. J. Am. Chem. Soc. 2003, 125, 4430-4431. [CrossRef]

62. Polsongkram, D.; Chamninok, P.; Pukird, S.; Chow, L.; Lupan, O.; Chai, G.; Khallaf, H.; Park, S.; Schulte, A. Effect of synthesis conditions on the growth of ZnO nanorods via hydrothermal method. Phys. B Condens. Matter 2008, 403, 3713-3717. [CrossRef]

63. Jiaqiang, X.; Yuping, C.; Daoyong, C.; Jianian, S. Hydrothermal synthesis and gas sensing characters of ZnO nanorods. Sens. Actuators B Chem. 2006, 113, 526-531. [CrossRef]

64. Pimentel, A.; Nunes, D.; Duarte, P.; Rodrigues, J.; Costa, F.M.; Monteiro, T.; Martins, R.; Fortunato, E. Synthesis of long ZnO nanorods under microwave irradiation or conventional heating. J. Phys. Chem. C 2014, 118, 14629-14639. [CrossRef]

65. Husham, M.; Hamidon, M.N.; Paiman, S.; Abuelsamen, A.A.; Farhat, O.F.; Al-Dulaimi, A.A. Synthesis of ZnO nanorods by microwave-assisted chemical-bath deposition for highly sensitive self-powered UV detection application. Sens. Actuators A Phys. 2017, 263, 166-173. [CrossRef]

66. Ferreira, S.H.; Deuermeier, J.; Sequeira, S.; Nunes, D.; Gonçalves, A.; Martins, R.; Monteiro, R.; Fortunato, E. Industrial Waste Residue Converted into Value-Added ZnO for Optoelectronic Applications. ACS Appl. Electron. Mater. 2020, 2, 1960-1969. [CrossRef]

67. Hamedani, N.F.; Mahjoub, A.R.; Khodadadi, A.A.; Mortazavi, Y. Microwave assisted fast synthesis of various ZnO morphologies for selective detection of CO, CH4 and ethanol. Sens. Actuators B Chem. 2011, 156, 737-742. [CrossRef]

68. Rai, P.; Song, H.-M.; Kim, Y.-S.; Song, M.-K.; Oh, P.-R.; Yoon, J.-M.; Yu, Y.-T. Microwave assisted hydrothermal synthesis of single crystalline $\mathrm{ZnO}$ nanorods for gas sensor application. Mater. Lett. 2012, 68, 90-93. [CrossRef]

69. Hassan, J.J.; Mahdi, M.A.; Chin, C.W.; Abu-Hassan, H.; Hassan, Z. Room-temperature hydrogen gas sensor with ZnO nanorod arrays grown on a quartz substrate. Phys. E Low-Dimens. Syst. Nanostruct. 2012, 46, 254-258. [CrossRef]

70. Liang, S.; Zhu, L.; Gai, G.; Yao, Y.; Huang, J.; Ji, X.; Zhou, X.; Zhang, D.; Zhang, P. Synthesis of morphology-controlled ZnO microstructures via a microwave-assisted hydrothermal method and their gas-sensing property. Ultrason. Sonochem. 2014, 21, 1335-1342. [CrossRef]

71. Ruiz Peralta, M.D.L.; Pal, U.; Zeferino, R.S. Photoluminescence (PL) Quenching and Enhanced Photocatalytic Activity of AuDecorated ZnO Nanorods Fabricated through Microwave-Assisted Chemical Synthesis. ACS Appl. Mater. Interfaces 2012, 4 , 4807-4816. [CrossRef]

72. Korake, P.V.; Kadam, A.N.; Garadkar, K.M. Photocatalytic activity of Eu ${ }^{3+}$-doped ZnO nanorods synthesized via microwave assisted technique. J. Rare Earths 2014, 32, 306-313. [CrossRef]

73. Hu, Y.; Lin, L.; Zhang, Y.; Wang, Z.L. Replacing a battery by a nanogenerator with 20 v output. Adv. Mater. 2012, 24, 110-114. [CrossRef]

74. Yan, J.; Jeong, Y.G. High Performance Flexible Piezoelectric Nanogenerators based on $\mathrm{BaTiO}_{3}$ Nanofibers in Different Alignment Modes. ACS Appl. Mater. Interfaces 2016, 8, 15700-15709. [CrossRef]

75. Lee, E.J.; Kim, T.Y.; Kim, S.W.; Jeong, S.; Choi, Y.; Lee, S.Y. High-performance piezoelectric nanogenerators based on chemicallyreinforced composites. Energy Environ. Sci. 2018, 11, 1425-1430. [CrossRef] 
76. Zhang, X.S.; Han, M.D.; Wang, R.X.; Zhu, F.Y.; Li, Z.H.; Wang, W.; Zhang, H.X. Frequency-multiplication high-output triboelectric nanogenerator for sustainably powering biomedical microsystems. Nano Lett. 2013, 13, 1168-1172. [CrossRef]

77. Dos Santos, A.; Pinela, N.; Alves, P.; Santos, R.; Fortunato, E.; Martins, R.; Águas, H.; Igreja, R. Piezoresistive E-Skin Sensors Produced with Laser Engraved Molds. Adv. Electron. Mater. 2018, 4, 1800182-1800192. [CrossRef]

78. Coelho, D. Solution Based Synthesis of ZnO Nanorods for Optoelectronic Applications. Master's Thesis, NOVA School of Science and Technology, NOVA University Lisbon, Lisbon, Portugal, 2019.

79. Lee, K.Y.; Kim, D.; Lee, J.-H.; Kim, T.Y.; Gupta, M.K.; Kim, S.-W. Unidirectional High-Power Generation via Stress-Induced Dipole Alignment from $\mathrm{ZnSnO}_{3}$ Nanocubes/Polymer Hybrid Piezoelectric Nanogenerator. Adv. Funct. Mater. 2014, 24, 37-43. [CrossRef]

80. Wang, G.; Xi, Y.; Xuan, H.; Liu, R.; Chen, X.; Cheng, L. Hybrid nanogenerators based on triboelectrification of a dielectric composite made of lead-free $\mathrm{ZnSnO}_{3}$ nanocubes. Nano Energy 2015, 18, 28-36. [CrossRef]

81. Ko, Y.H.; Nagaraju, G.; Lee, S.H.; Yu, J.S. PDMS-based Triboelectric and Transparent Nanogenerators with ZnO Nanorod Arrays. ACS Appl. Mater. Interfaces 2014, 6, 6631-6637. [CrossRef]

82. Lee, S.; Ko, W.; Oh, Y.; Lee, J.; Baek, G.; Lee, Y.; Sohn, J.; Cha, S.; Kim, J.; Park, J.; et al. Triboelectric energy harvester based on wearable textile platforms employing various surface morphologies. Nano Energy 2015, 12, 410-418. [CrossRef]

83. Xiong, J.; Cui, P.; Chen, X.; Wang, J.; Parida, K.; Lin, M.-F.; Lee, P.S. Skin-touch-actuated textile-based triboelectric nanogenerator with black phosphorus for durable biomechanical energy harvesting. Nat. Commun. 2018, 9, 4280. [CrossRef]

84. Xia, K.; Zhu, Z.; Fu, J.; Li, Y.; Chi, Y.; Zhang, H.; Du, C.; Xu, Z. A triboelectric nanogenerator based on waste tea leaves and packaging bags for powering electronic office supplies and behavior monitoring. Nano Energy 2019, 60, 61-71. [CrossRef]

85. Karan, S.K.; Maiti, S.; Agrawal, A.K.; Das, A.K.; Maitra, A.; Paria, S.; Bera, A.; Bera, R.; Halder, L.; Mishra, A.K.; et al. Designing high energy conversion efficient bio-inspired vitamin assisted single-structured based self-powered piezoelectric/wind/acoustic multi-energy harvester with remarkable power density. Nano Energy 2019, 59, 169-183. [CrossRef]

86. Lee, J.-H.; Yoon, H.-J.; Kim, T.Y.; Gupta, M.K.; Lee, J.H.; Seung, W.; Ryu, H.; Kim, S.-W. Micropatterned P(VDF-TrFE) Film-Based Piezoelectric Nanogenerators for Highly Sensitive Self-Powered Pressure Sensors. Adv. Funct. Mater. 2015, 25, 3203-3209. [CrossRef]

87. Zhu, Y.; Yang, B.; Liu, J.; Wang, X.; Wang, L.; Chen, X.; Yang, C. A flexible and biocompatible triboelectric nanogenerator with tunable internal resistance for powering wearable devices. Sci. Rep. 2016, 6, 22233. [CrossRef] [PubMed]

88. Pu, X.; Liu, M.; Chen, X.; Sun, J.; Du, C.; Zhang, Y.; Zhai, J.; Hu, W.; Wang, Z.L. Ultrastretchable, transparent triboelectric nanogenerator as electronic skin for biomechanical energy harvesting and tactile sensing. Sci. Adv. 2017, 3, e1700015. [CrossRef] [PubMed] 